\title{
HEPES buffer in ovary-transportation medium influences developmental competence of cattle oocytes
}

\author{
Sh. Bohlooli ${ }^{\#}$ Ş. Bozoğlu \& F. Cedden \\ Department of Animal Science, Faculty of Agriculture, University of Ankara, Ankara, Turkey
}

(Received 20 July 2014; Accepted 8 October 2015; First published online 17 December 2015)

\author{
Copyright resides with the authors in terms of the Creative Commons Attribution 2.5 South African Licence. \\ See: http://creativecommons.org/licenses/by/2.5/za \\ Condition of use: The user may copy, distribute, transmit and adapt the work, but must recognise the authors and the South African \\ Journal of Animal Science.
}

\begin{abstract}
This study was conducted to investigate the effects of ovary transportation in a semi-complex medium containing HEPES at different temperatures on the developmental competence and the quality of in vitroproduced embryos. The cattle ovaries were transported in normal saline (NS), phosphate buffer saline (PBS), K simplex optimization medium (KSOM), Chatot-Ziomek-Bavister medium (CZB) and Charles Rosenkrans medium (CR1) at various temperatures $\left(38^{\circ} \mathrm{C}, 25^{\circ} \mathrm{C}\right.$ and $\left.4{ }^{\circ} \mathrm{C}\right)$. The developmental competence of retrieved cumulus oocyte complexes (COCs) was evaluated by maturation, fertilization, morula and blastocyst formation and numbers of inner cell mass (ICM) and trophectoderm (TE) cells. The COC maturation rate was affected by medium and temperature. It was found that $4{ }^{\circ} \mathrm{C}$ resulted in a higher maturation $(81.0 \pm 4.75)$ rate than other transportation temperatures. The CR1 $(80.5 \pm 6.66)$ and KSOM $(80.2 \pm 6.15)$ gave a better maturation rate than the others. Fertilization rate, which was evaluated by cleavage rate, was not affected by transportation temperature. However, the transporting medium had a significant effect on the fertilization rate. Moreover, CR1 $(43.6 \pm 4.60), \operatorname{KSOM}(43.2 \pm 4.86)$ and CZB $(41.1 \pm 4.86)$ media gave higher percentages of cleaved embryos. There was no significant difference in morula and blastocyst formation rate or in ICM and TE cell counts regarding transportation factors. In conclusion, the transport of ovaries in CR1 at $4{ }^{\circ} \mathrm{C}$ is effective for maintaining early developmental competence of cattle oocytes.
\end{abstract}

Keywords: Cattle embryo, in vitro embryo production, ovary transportation

\#Corresponding author: sbohlooli@ankara.edu.tr

\section{Introduction:}

The oocytes from slaughtered animal ovaries show weakened developmental competence compared with those collected from live animals by ovum pick-up (Baldassarre et al., 2002; Neglia et al., 2003; Manjunatha et al., 2008). The differences in the quality of the oocytes may be associated with the stresses imposed during in vitro production (IVP), which begins from ovary removal. Practical problems often encountered are the effects of transportation, preservation medium and temperature (Yuge et al., 2003; Pedersen et al., 2004; Wongsrikeao et al., 2005). The $0.9 \%$ saline solution and the PBS are used extensively as ovary, cumulus oocyte complexes (COCs), zygote and embryo transportation media in goats (Silva et al., 2004; Rodriguez-Dorta et al., 2007), sheep (Smith et al., 1994; Wani et al., 2000; Shi et al., 2009), buffaloes (Amer et al., 2008; Ubaidullah et al., 2009), cows (Niemann, 1991; Thibodeaux et al., 1992; Martino et al., 1996; Schernthaner et al., 1997; Yang, 2002), sows (Mattioli et al., 1988; Westhof et al., 1991; Whitaker \& Knight, 2004) and other animals (Nureddin et al., 1990; Jewgenow et al., 1998). However, studies have demonstrated that glucose in the presence of phosphate is responsible for the delay or developmental arrest of cleavage stage embryos in cultures (Schini \& Bavister, 1988; Chatot et al., 1989; Thompson et al., 1992). It was also shown that increasing phosphate in the medium did not improve embryo development. In contrast, complete elimination of phosphate improved developmental competence (Schini \& Bavister, 1988). Nevertheless, it is not known whether phosphate in ovary-transportation media has a negative or positive effect on oocyte maturation and developmental competence. On the other hand, improper transporting and preserving conditions might cause failure in oocyte maturation and developmental competence. A change in the storage temperature and preservation solution during ovary transport has great effect on the developmental competence of oocytes following in vitro fertilization (IVF) or somatic cell nuclear transfer (SCNT) (Choi et al., 2006; Kim et al., 2006; Chaves et al., 2008; Lopes et al., 2009). Previous researchers showed that oocyte quality affects the IVP efficiency in most species. Nevertheless, the effects of ovary-transporting media on the developmental competence of the oocyte have not been investigated. 
The effects of physiological saline and PBS use on oocyte quality and developmental competence for ovary-transportation medium at different temperatures $\left(4^{\circ} \mathrm{C}, 15^{\circ} \mathrm{C}, 25^{\circ} \mathrm{C}, 33^{\circ} \mathrm{C}\right.$, and $\left.35^{\circ} \mathrm{C}\right)$ have been investigated extensively (Wongsrikeao et al., 2005; Kim et al., 2006; Wang et al., 2011). However, there is little information about partially complex media use, such as KSOM and CZB, on the developmental competence of rescued COCs. In addition, commonly used ovary-transporting media, such as NS and PBS, lack suitable buffers. It is well known that glycolysis is the major anaerobic pathway for ATP production, which should result in increasing lactate levels and decreasing $\mathrm{pH}$ under hypoxic conditions. Hypoxic and acidic conditions have adverse effects on cell membrane permeability, net electric charge (Patel et al., 1973) and chromosomal instability (Schomack \& Gillies, 2003). Therefore, a lack of buffer systems in ovarytransporting media may be an important factor that influences the subsequent developmental competence of recovered COCs. From the available buffer systems for biological research, HEPES (N-(2-hydroxyethyl)piperazine- $\mathrm{N}$ '-(2- ethanesulfonic acid) is one of the best all-purpose buffers. At most biological pHs the molecule is zwitterionic, and is effective as a buffer at $\mathrm{pH} 6.8$ to 8.2. HEPES has been used in a wide variety of applications, including tissue culture, but it has not been studied in ovary transportation media. Thus, the aim of this work was to study the effects of semi-complex transporting media (including HEPES) at various temperatures on the post-transportation characteristics of COCs and preimplantation embryos.

\section{Material and Methods}

Cow ovaries of unknown reproductive status were collected from a local slaughterhouse in Ankara, Turkey. The ovaries were transported to the laboratory within $2-3 \mathrm{~h}$ in five media, namely NS, PBS, KSOM, CZB and CR1 (Table 1) and three temperatures $\left(4^{\circ} \mathrm{C}, 25^{\circ} \mathrm{C}, 38^{\circ} \mathrm{C}\right.$ ). Then the ovaries were sliced (Das et al., 1996; Bohlooli et al., 2015) and rinsed by maturation medium at $38^{\circ} \mathrm{C}$ in order to obtain COCs (Soto et al., 2003). Classification of the recovered COCs was performed according to cumulus corona cell investment and morphology of the ooplasm, as described by Rahman et al. (2007). Healthy COCs or naked oocytes with finely granulated and homogeneous ooplasm (Grade A - D) were selected (Rahman et al., 2007) for in vitro maturation (IVM).

Table 1 Composition of ovary-transporting media

\begin{tabular}{lccccc}
\hline Component $(\mathbf{m M})$ & NS & PBS & KSOM & CZB & CR1 \\
\hline $\mathrm{NaCl}$ & 150 & 130 & 125 & 100 & 135 \\
$\mathrm{KCl}$ & - & 2.70 & 2.50 & 4.86 & 10 \\
$\mathrm{Na}_{2} \mathrm{HPO}_{4}$ & - & 10 & - & - & - \\
$\mathrm{KH}_{2} \mathrm{PO}_{4}$ & - & 1.8 & 0.35 & 1.17 & - \\
$\mathrm{MgSO}_{4}$ & - & - & 10.2 & 1.18 & - \\
$\mathrm{CaCl}_{2} 2 \mathrm{H}_{2} \mathrm{O}$ & - & - & 1.71 & 1.71 & - \\
$\mathrm{Na}$ Lactate & - & - & 10 & 30.10 & - \\
$\mathrm{Na}$ Pyruvate & - & - & 0.20 & 0.26 & - \\
$\mathrm{HEPES}$ & - & - & 10 & 10 & 10 \\
Glucose & - & - & 0.20 & - & - \\
L-glutamine & - & - & 1 & 1 & - \\
EDTA & - & - & 0.01 & 0.1 & \\
Gentamicin $(\mu \mathrm{g} / \mathrm{mL})$ & 50 & 50 & 50 & 50 & 50 \\
& & & & & \\
\hline
\end{tabular}

NS: normal saline; PBS: phosphate buffered saline; KSOM: K simplex optimization medium; CZB: Chatot-ZiomekBavister medium; CR1: Charles Rosenkrans medium.

The selected COCs were then washed three times with maturation medium and cultured in groups of 20 under mineral oil in $100 \mu \mathrm{L}$ TCM-199 medium supplemented with $0.4 \mathrm{mM}$ sodium pyruvate, $1 \mathrm{mM}$ L-glutamine, $100 \mu \mathrm{M}$ cysteamine, 10\% (v/v) foetal bovine serum, $20 \mu \mathrm{g} \mathrm{FSH} / \mathrm{mL}, 2 \mu \mathrm{g}$ oestradiol $/ \mathrm{mL}$ and 50 $\mu \mathrm{g}$ gentamycin $/ \mathrm{mL}$. The COCs were incubated at $38.5^{\circ} \mathrm{C}$ in a humidified atmosphere of $5 \% \mathrm{CO}_{2}, 5 \% \mathrm{O}_{2}$ and $90 \% \mathrm{~N}_{2}$. Matured oocytes were determined by cumulus expansion. The rates of oocytes exhibiting cumulus 
expansion were determined at $24 \mathrm{~h}$ after IVM. The degree of cumulus expansion was assessed by the morphology of the cumulus oophorous, which is described by Kobayashi et al. (1994). Briefly, category C: no expansion was seen; category B: cumulus cells were non-homogeneously spread and clustered cells were still observed; category A: cumulus cells were homogeneously spread and clustered cells were no longer present.

After maturation, batches of 20 COCs were exposed to co-culture with sperm selected with the Percoll density gradient method with a concentration of approximately $1 \times 10^{6} \mathrm{sperm} / \mathrm{mL}$ in $200 \mu \mathrm{L}$ droplet of fertilization medium, and incubated at $38.5{ }^{\circ} \mathrm{C}$ with $5 \% \mathrm{CO}_{2}, 5 \% \mathrm{O}_{2}$ and $90 \% \mathrm{~N}_{2}$. The fertilization medium was Fert-SOF, supplemented with $100 \mathrm{IU}$ penicillin/mL, $100 \mu \mathrm{g}$ streptomycin/mL, $2 \mathrm{mM}$ caffeine and $10 \mu \mathrm{g}$ heparin/mL. After $18 \mathrm{~h}$ co-incubation, the presumptive zygotes were removed from the fertilization medium, denoted, washed three times in synthetic oviduct fluid-BE1 medium (SOF-BE1) and cultured in a humidified atmosphere of $5 \% \mathrm{CO}_{2}, 5 \% \mathrm{O}_{2}$ until day $7-8$ after IVF. Half of the embryo culture medium was refreshed every $48 \mathrm{~h}$ and $10 \%$ foetal bovine serum was added at day 2 of IVC. The cleavage rate was evaluated at day 3 post insemination. The morula and blastocyst rate was recorded at day 8 after IVF.

Differential staining of ICM and TE was done using a method described by Thouas et al. (2001) with minor modifications to calculate ICM and TE cells. Briefly, blastocysts were removed from the culture with as little medium as possible, and placed in the $30 \mu \mathrm{g}$ propidium iodide solution $/ \mathrm{mL}$ phosphate buffer saline/ polyvinylpyrrolidone (PBS/PVP) containing 1\% Triton X-100 (v/v) for 30 seconds. After washing three times in PBS/PVP, the embryos were incubated in Hoechst solution, containing $10 \mu \mathrm{g}$ Hoechst 33342/mL in PBS/PVP, supplemented with 4\% (w/v) paraformaldehyde for $30 \mathrm{~min}$. After washing, the embryos were transferred onto microscope slides in a small volume of glycerol solution, and covered with the cover slip supported by four small droplets of vaseline/paraffin. The embryos were viewed as soon as possible by UV light under a Leica DMIL LED fluorescence microscope. After imaging, total stained nuclei were counted. In this dyeing method the ICM cells were appeared blue, while TE cells were red.

This study was performed in $3 \times 5$ factorial design (temperature at three levels and ovary-transporting medium at five levels). Data are expressed as mean \pm SD. The percentages of maturation, cleavage, morula and blastocyst rates, ICM and TE cell numbers from each treatment were used for statistical analysis. After testing normality and arc-sine transformation of proportional data, analysis of variance (ANOVA) was used to assess differences. The Duncan test was used to compare means $(P<0.05)$. The statistical analysis was performed by R program, and the Duncan test was performed with the Agricolae package program (Seefeld \& Linder, 2007; de Mendiburu, 2014).

\section{Results and Discussion}

This study revealed that ovary-transporting temperature affects maturation rate of COCs $(P<0.01)$. Table 2 summarizes the effects of three transportation temperatures in five media on the maturation rate of bovine oocytes. The NS, CR1, KSOM media at $4{ }^{\circ} \mathrm{C}$ provided a higher percentage of category A matured oocytes compared with other treatments. The percentage of non-expanded cumulus complex was higher in PBS $(20.7 \pm 1.88)$ at $38^{\circ} \mathrm{C}$ and lower in CZB (10.11 \pm 2.58$)$, CR1 (10.27 \pm 2.74$)$ and KSOM (10.87 \pm 1.37$)$ at $4^{\circ} \mathrm{C}$.

As illustrated in Figures 1 and 2, when factors were analysed independently, $4^{\circ} \mathrm{C}(81.0 \pm 6.80)$ was found better than other transporting temperatures $(P<0.0008)$. Also CR1 $(80.5 \pm 6.66)$ and KSOM $(80.2 \pm$ 6.15) together were better than other transporting media $(P<0.0008)$ in terms of category $A$ matured oocytes. Regarding category B of expanding COC rate, it was not affected by the temperature $(P=0.083)$, but the transporting medium had a significant effect $(P=0.024)$. As shown in Table 2 , the rate of nonmatured oocytes of category $\mathrm{C}$ varied significantly with transporting temperature $(P<0.0001)$ and medium $(P=0.0003)$.

The IVF of oocytes was affected by transporting media $(P<0.0001)$, but not temperature $(P=0.17)$. The CR1 group at $4{ }^{\circ} \mathrm{C}(45.0 \pm 1.67)$ and $38^{\circ} \mathrm{C}(44.2 \pm 8.04)$ provided a higher rate of fertilization compared with PBS $(14.2 \pm 6.29)$ at $25^{\circ} \mathrm{C}$ (Table 2$)$. Fertilization rate was not affected by transporting temperature $(P=$ 0.17). However, transporting medium had a significant effect on the fertilization rate $(P<0.001)$. Figure 3 shows higher cleavage rates in CR1 (43.6 \pm 4.60$), \mathrm{KSOM}(43.2 \pm 5.26)$ and CZB $(41.1 \pm 4.86)$, while the lowest cleavage rate was observed in PBS (17.7 \pm 6.75$)$.

As shown in Table 3, the morula and blastocyst formation rates were not affected by the ovarytransportation medium or temperature $(P>0.05)$. Also, it can be presumed that the mean of ICM and TE cells was not influenced by ovary-transporting medium or temperature $(P>0.05)$.

This is the first study to compare simple and semi-complex media containing HEPES buffer. It has shown that semi-complex media resulted in higher maturation and cleavage rates (Table 2 and Figures 1 3). It was revealed that the ovary-transporting medium and temperature both play important roles in the 
Table 2 Mean ( \pm SD) maturation rate of cumulus oocyte complexes (COCs) and cleavage in various ovarytransporting media and at different temperatures

\begin{tabular}{|c|c|c|c|c|c|c|}
\hline \multirow{2}{*}{ Temperature } & \multirow{2}{*}{ Medium } & \multirow{2}{*}{$\mathbf{N}$} & \multicolumn{3}{|c|}{ Category (\%) } & \multirow{2}{*}{ Cleavage (\%) } \\
\hline & & & A & B & C & \\
\hline \multirow{5}{*}{$38^{\circ} \mathrm{C}$} & NS & 180 & $69.80^{\mathrm{bcd}} \pm 5.36$ & $9.68^{a b c} \pm 5.13$ & $20.19^{a b} \pm 1.06$ & $31.67^{\mathrm{bc}} \pm 5.20$ \\
\hline & PBS & 180 & $66.84^{\mathrm{cd}} \pm 3.05$ & $12.43^{\mathrm{ab}} \pm 3.16$ & $20.72^{a} \pm 1.88$ & $15.83^{d} \pm 8.04$ \\
\hline & KSOM & 180 & $80.69^{\mathrm{ab}} \pm 0.29$ & $4.55^{\mathrm{C}} \pm 2.68$ & $14.76^{\text {bcde }} \pm 2.39$ & $44.17^{\mathrm{a}} \pm 6.29$ \\
\hline & CZB & 180 & $75.15^{\mathrm{abcd}} \pm 1.31$ & $7.85^{\mathrm{ab}} \pm 0.36$ & $17.00^{\mathrm{abcd}} \pm 0.95$ & $44.17^{a} \pm 3.82$ \\
\hline & CR1 & 180 & $79.08^{\mathrm{ab}} \pm 1.29$ & $6.18^{\mathrm{ab}} \pm 1.99$ & $14.74^{\text {bcde }} \pm 0.70$ & $44.17^{\mathrm{a}} \pm 1.67$ \\
\hline \multirow{5}{*}{$25^{\circ} \mathrm{C}$} & NS & 180 & $73.08^{\mathrm{abcd}} \pm 4.14$ & $8.10^{b c} \pm 1.52$ & $18.82^{\mathrm{abc}} \pm 4.33$ & $24.17^{\mathrm{cd}} \pm 8.78$ \\
\hline & PBS & 180 & $65.74^{d} \pm 15.81$ & $15.46^{a} \pm 11.69$ & $18.80^{\mathrm{abc}} \pm 7.22$ & $14.17^{d} \pm 6.29$ \\
\hline & KSOM & 180 & $77.99^{\mathrm{ab}} \pm 3.83$ & $6.62^{\mathrm{bc}} \pm 1.54$ & $15.40^{\text {bcde }} \pm 2.42$ & $41.67^{\mathrm{ab}} \pm 8.04$ \\
\hline & CZB & 180 & $72.78^{\mathrm{abcd}} \pm 5.85$ & $12.0^{\mathrm{abc}} \pm 5.24$ & $15.22^{\text {bcde }} \pm 0.77$ & $38.33^{\mathrm{ab}} \pm 7.22$ \\
\hline & CR1 & 180 & $78.70^{\mathrm{ab}} \pm 3.51$ & $8.31^{\mathrm{abc}} \pm 2.44$ & $13.00^{\mathrm{de}} \pm 2.41$ & $41.67^{\mathrm{ab}} \pm 8.04$ \\
\hline \multirow{5}{*}{$4^{\circ} \mathrm{C}$} & NS & 180 & $80.95^{a} \pm 7.10$ & $5.35^{\mathrm{ab}} \pm 3.26$ & $13.70^{\text {cde }} \pm 3.85$ & $20.00^{d} \pm 3.33$ \\
\hline & PBS & 180 & $76.92^{\mathrm{abc}} \pm 5.14$ & $7.92^{\mathrm{bc}} \pm 0.69$ & $15.17^{\text {bcde }} \pm 4.58$ & $23.06^{\mathrm{cd}} \pm 3.37$ \\
\hline & KSOM & 180 & $81.83^{a} \pm 4.13$ & $7.29^{\mathrm{ab}} \pm 3.11$ & $10.87^{\mathrm{e}} \pm 1.37$ & $43.89^{a} \pm 0.96$ \\
\hline & CZB & 180 & $81.96^{a} \pm 4.57$ & $7.94^{\mathrm{ab}} \pm 2.27$ & $10.11^{\mathrm{e}} \pm 2.58$ & $40.83^{\mathrm{ab}} \pm 1.44$ \\
\hline & CR1 & 180 & $83.57^{a} \pm 2.48$ & $5.49^{\mathrm{ab}} \pm 0.59$ & $10.27^{\mathrm{e}} \pm 2.74$ & $45.00^{a} \pm 1.67$ \\
\hline
\end{tabular}

a,b,c,d,e Means in a column with different superscripts differ significantly at $P<0.05$.

NS: normal saline; PBS: phosphate buffered saline; KSOM: K simplex optimization medium; CZB: Chatot, Ziomek, Bavister medium; CR1: Charles Rosenkrans medium.

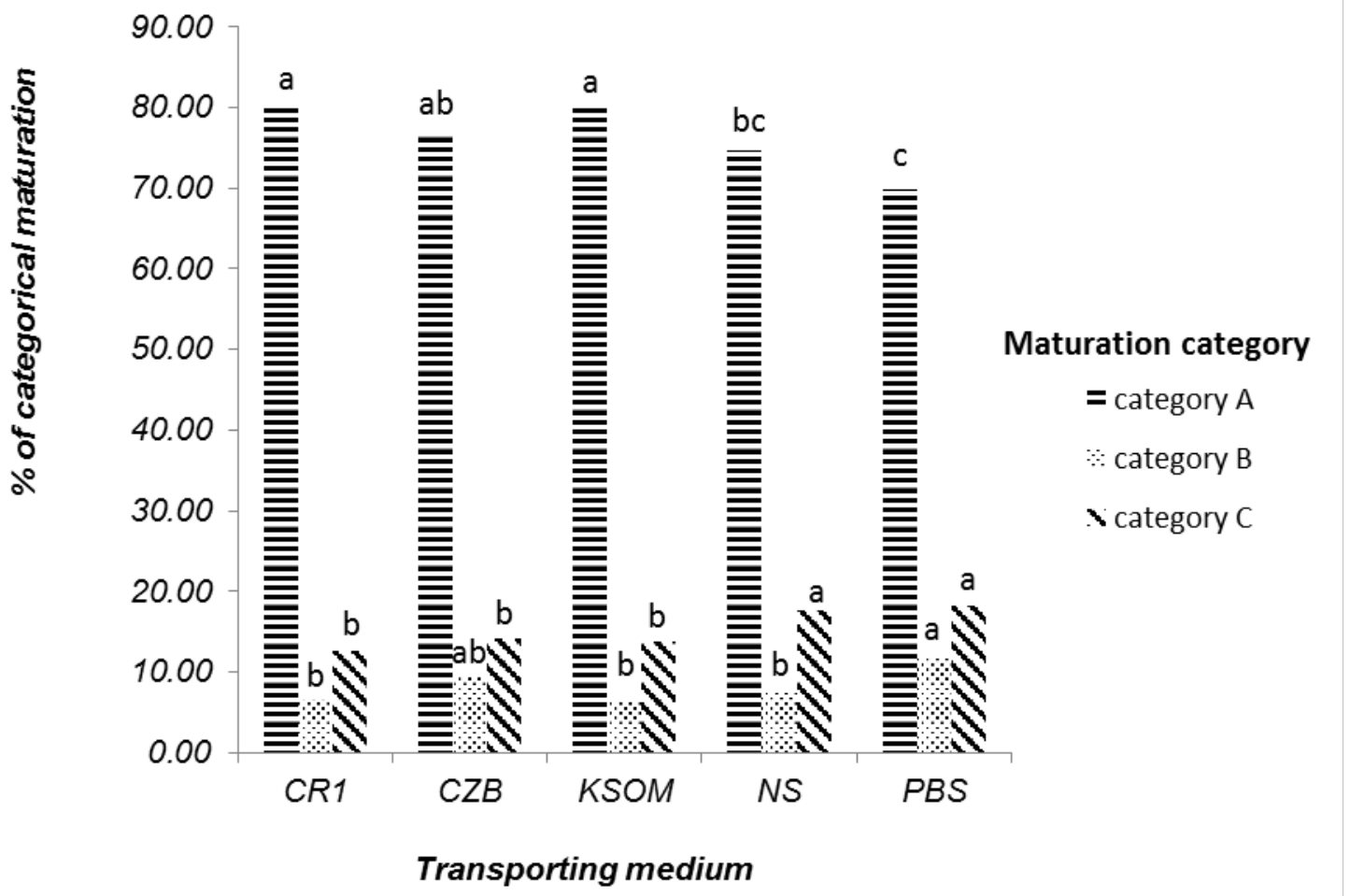

Figure 1 Mean matured (\%) cumulus oocyte complexes (COCs) in various ovary-transporting media. NS: normal saline; PBS: phosphate buffered saline; KSOM: K simplex optimization medium; CZB: Chatot, Ziomek, Bavister medium; CR1: Charles Rosenkrans medium. 


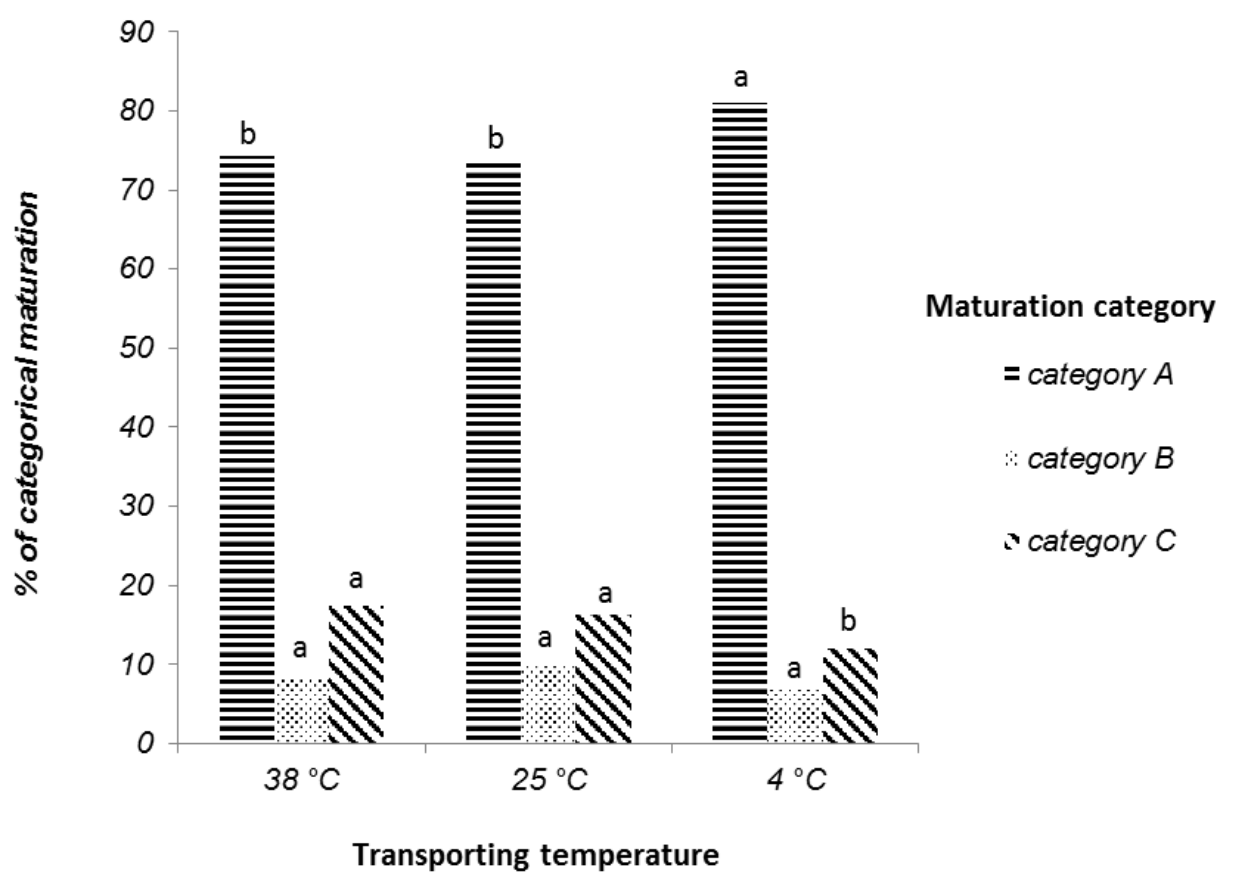

Figure 2 Mean matured (\%) cumulus oocyte complexes (COCs) at various ovary-transporting temperatures.

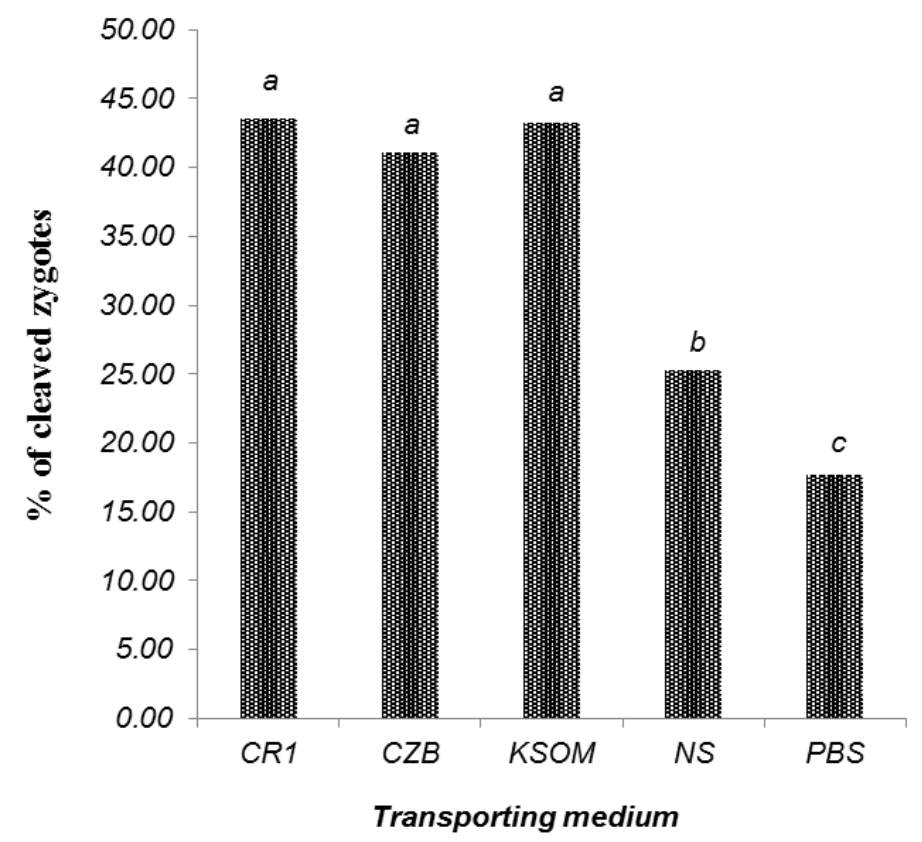

Figure 3 Mean cleavage rate (\%) of in vitro-matured oocytes in different ovary-transporting media. NS: normal saline; PBS: phosphate buffered saline; KSOM: K simplex optimization medium; CZB: Chatot, Ziomek, Bavister medium; CR1: Charles Rosenkrans medium.

maturation rate of recovered COCs. Transporting media and temperature are both important in early developmental competence, but have no significant effects on morula and blastocyst formation. Neither ICM nor TE cell numbers were influenced by the test factors (Table 3). There were no interactions between ovarytransporting medium and temperature. 
As illustrated in Figure 2, ovary transporting at $4{ }^{\circ} \mathrm{C}$ resulted in a high ratio of matured oocytes. This result is in accordance with those of Yuge et al. (2003), who reported that porcine ovaries being exposed to $25^{\circ} \mathrm{C}$ or less before aspiration of oocytes might have an adverse effect on their subsequent IVM. But there is a consonance between Taş et al. (2006) and Evecen et al. (2010), who investigated the effect of ovarytransporting temperature at $37^{\circ} \mathrm{C}$ and $4^{\circ} \mathrm{C}$ on canine oocyte maturation, and found that $4{ }^{\circ} \mathrm{C}$ should provide more matured oocytes. A study conducted by Matsushita et al. (2004) revealed that transporting ovine ovaries at $10^{\circ} \mathrm{C}$ had no effect on the developmental competence of recovered COCs. Wang et al. (2011) demonstrated that $15^{\circ} \mathrm{C}$ was better than $30^{\circ} \mathrm{C}$ and $35^{\circ} \mathrm{C}$ in terms of reduction of the apoptosis index, but there were no significant differences in cleavage and blastocyst development. The high maturation rate that was achieved at $4{ }^{\circ} \mathrm{C}$ may be related to the low temperature, which should reduce cellular metabolism (Chaves et al., 2008), minimize energy consumption, and slow down the tissue autolysis rate (Salehi et al., 2004). In addition, the efficiency of enzymes and incidence of apoptosis decreases at low temperatures (Pedersen et al., 2004). In term of cold injury, COCs may be protected from cold damage because of the intrafollicular environment (Matsushita et al., 2004).

Table 3 Mean ( \pm SD) morula and blastocyst (\%) formation rate and ratio of inner cell mass to trophectoderm cells of various ovary-transporting media and temperatures

\begin{tabular}{|c|c|c|c|c|c|c|c|}
\hline Temp. & Medium & Morula & Blastocyst & $\begin{array}{c}\text { Total } \\
\text { embryo }\end{array}$ & ICM & TE & ICM/TE \\
\hline \multirow{5}{*}{$38^{\circ} \mathrm{C}$} & NS & $21.1 \pm 3.53$ & $10.3 \pm 2.70$ & $31.1 \pm 3.50$ & $33.3 \pm 2.06$ & $113.85 \pm 8.62$ & $0.29 \pm 0.02$ \\
\hline & PBS & $25.0 \pm 5.00$ & $10.0 \pm 10.00$ & $35.0 \pm 8.66$ & $31.5 \pm 2.12$ & $113.0 \pm 4.24$ & $0.28 \pm 0.03$ \\
\hline & KSOM & $22.4 \pm 2.51$ & $13.2 \pm 1.95$ & $35.6 \pm 3.85$ & $33.4 \pm 3.21$ & $111.6 \pm 2.15$ & $0.30 \pm 0.03$ \\
\hline & CZB & $24.4 \pm 7.47$ & $11.5 \pm 5.77$ & $35.9 \pm 2.24$ & $27.8 \pm 13.97$ & $121.0 \pm 11.42$ & $0.24 \pm 0.12$ \\
\hline & CR1 & $28.2 \pm 4.16$ & $7.6 \pm 3.59$ & $35.8 \pm 0.89$ & $35.0 \pm 2.83$ & $110.8 \pm 9.32$ & $0.32 \pm 0.05$ \\
\hline \multirow{5}{*}{$25^{\circ} \mathrm{C}$} & NS & $23.3 \pm 6.66$ & $14.0 \pm 3.54$ & $37.3 \pm 3.49$ & $31.0 \pm 2.16$ & $120.0 \pm 4.32$ & $0.26 \pm 0.01$ \\
\hline & PBS & $19.4 \pm 17.35$ & $15.3 \pm 16.84$ & $34.7 \pm 2.41$ & $35.0 \pm 2.83$ & $108.0 \pm 15.56$ & $0.33 \pm 0.07$ \\
\hline & KSOM & $23.1 \pm 8.13$ & $10.7 \pm 9.27$ & $33.8 \pm 4.47$ & $32.3 \pm 2.22$ & $114.0 \pm 5.72$ & $0.28 \pm 0.03$ \\
\hline & CZB & $26.0 \pm 3.06$ & $13.4 \pm 6.53$ & $39.4 \pm 3.55$ & $33.7 \pm 3.98$ & $114.7 \pm 12.08$ & $0.30 \pm 0.06$ \\
\hline & CR1 & $26.9 \pm 11.76$ & $9.5 \pm 12.09$ & $36.3 \pm 4.10$ & $31.5 \pm 2.89$ & $116.8 \pm 11.47$ & $0.27 \pm 0.05$ \\
\hline \multirow{5}{*}{$4^{\circ} \mathrm{C}$} & NS & $19.8 \pm 5.36$ & $20.4 \pm 8.04$ & $40.1 \pm 2.68$ & $33.0 \pm 3.56$ & $113.8 \pm 8.34$ & $0.29 \pm 0.05$ \\
\hline & PBS & $19.0 \pm 12.45$ & $19.4 \pm 17.35$ & $38.4 \pm 5.62$ & $32.4 \pm 4.28$ & $121.0 \pm 8.00$ & $0.27 \pm 0.05$ \\
\hline & KSOM & $25.8 \pm 11.99$ & $12.8 \pm 11.75$ & $38.6 \pm 0.25$ & $31.80 \pm 2.28$ & $115.4 \pm 5.18$ & $0.28 \pm 0.03$ \\
\hline & CZB & $13.9 \pm 12.73$ & $17.3 \pm 15.57$ & $31.2 \pm 5.46$ & $31.3 \pm 4.03$ & $116.8 \pm 12.61$ & $0.27 \pm 0.05$ \\
\hline & CR1 & $26.7 \pm 4.77$ & $10.9 \pm 10.72$ & $37.5 \pm 6.16$ & $32.2 \pm 4.09$ & $115.4 \pm 12.56$ & $0.28 \pm 0.06$ \\
\hline
\end{tabular}

NS: normal saline; PBS: phosphate buffered saline; KSOM: K simplex optimization medium;

CZB: Chatot, Ziomek, Bavister medium; CR1: Charles Rosenkrans medium.

The results have shown that CR1 and KSOM provide superior maturation rates to the others (Figure 1). The effect of transporting medium on maturation rate was investigated, among others, by Lin et al. (2011), who focused on the outcomes of pig ovary transportation in PBS, BCS and NS for defining the maturation rate of recovered oocytes. It showed that PBS $(72.6 \pm 4.0)$ and BCS $(71.5 \pm 0.5)$ media resulted in a higher maturation rate than a saline $(65.6 \pm 1.1)$ solution. It was suggested that this difference might be related to other components in PBS and BCS. As shown in Table 1, the components of CR1 are similar to NS, which was complemented by $10 \mathrm{mM}$ HEPES, but KSOM was a relatively more complex media than others. Therefore, these differences may be derived from HEPES buffer. The BCS medium has a bicarbonate buffer (Silva et al., 2000), which may be effective in a $\mathrm{CO}_{2}$-rich environment. But in these studies the authors replaced bicarbonate with HEPES, which acts independently of environmental $\mathrm{CO}_{2}$. $\mathrm{Moreover}$ it contains pKas $\left(4^{\circ} \mathrm{C}=7.77\right.$, pKa $25^{\circ} \mathrm{C}=7.48$ and pka $37^{\circ} \mathrm{C}=7.31$ ), which may provide a more suitable environment for these trial conditions and temperatures (Anonymous, 2008).

While it has been believed that storage close to body temperature causes cellular autolysis (Pedersen et al., 2004), which decreases the maturation of bovine oocytes and adversely affects the developmental 
competence of oocytes (Evecen et al., 2010), the cleavage rate of matured oocytes was high in CR1, CZB and $\mathrm{KSOM}$ at $38^{\circ} \mathrm{C}$. These findings are in agreement with those reported by Love et al. (2003) and Yuge et al. (2003), but contrast those of Wongsrikeao et al. (2005) and Evecen et al. (2010). Some disparities might be caused by long storage time, which was studied by these investigators. This might be because of the HEPES buffering system in the media used in this study that maintained enzymes, hormones and $\mathrm{pH}$ at physiological range. Lack of suitable buffers resulted in $\mathrm{pH}$ decreases, which increased fragmented DNA nuclei significantly. It was suggested that the plasma membrane of oocytes was highly permeable to $\mathrm{H}^{+}$ions without any regulatory mechanism (Wongsrikeao et al., 2005). If external $\mathrm{pH}$ was maintained by increasing buffering capacity, the expulsion of protons would continue for a prolonged period, thus reducing the drop in intracellular pH buffers (Salehi et al., 2004), which has biological importance in determining the net electric charge of amino acids, which affects cell membrane permeability (Patel et al., 1973).

Table 3 shows that morula and blastocyst formation was not affected by transportation medium or temperature, which is in agreement with Wang et al. (2011), who reported that the blastocyst formation rate was not affected by the transporting temperature. However, in terms of total cell numbers, the results of this study was contradictory to these authors (Wang et al., 2011), in which the total cell numbers in SCNT embryos were higher in day 7 blastocysts from ovaries stored at $15^{\circ} \mathrm{C}$ than in those from ovaries stored at $35^{\circ} \mathrm{C}$ or $25^{\circ} \mathrm{C}$. It seems that ovary-transporting conditions affect the early and late stages of developmental competence (Guignot et al., 1999), but the quality of in vitro-produced embryos was not affected by transporting temperature and medium.

\section{Conclusion}

This study showed that ovary-transporting media and temperature significantly affected the maturation of bovine oocytes. The result revealed that $4{ }^{\circ} \mathrm{C}$ in the transportation temperature showed an optimal maturation rate. $\mathrm{CR} 1$ and KSOM media also resulted in a higher maturation rate. But the cleavage rate not affected by transportation temperature and only effected by transporting media which was higher in CR1, CZB and KSOM. Therefore, it was concluded that adding HEPES is beneficial to ovary transportation. The use of media such as CR1, CZB and KSOM that contain HEPES at a temperature of $4^{\circ} \mathrm{C}$ could be advised in ovary transportation in order to maintain subsequent IVM and cleavage rate.

\section{Acknowledgement}

This study was supported by grants from Ankara University Scientific Research Projects (Project Number: 12B4347012).

\section{References}

Amer, H., Hegab, A. \& Zaabal, S., 2008. Effects of ovarian morphology on oocyte quantity and quality, granulosa cells, in vitro maturation, and steroid hormone production in buffaloes. Anim. Reprod. 5 $(1 / 2), 55-62$.

Anonymous, 2008. Biological buffers. Retrieved 5-10-2014, from AppliChem: https://www.applichem.com/fileadmin/Broschueren/BioBuffer.pdf

Baldassarre, H., Wang, B., Kafidi, N., Keefer, C., Lazaris, A. \& Karatzas, C., 2002. Advances in the production and propagation of transgenic goats using laparoscopic ovum pick-up and in vitro embryo production technologies. Theriogenology 57, 275-284.

Bohlooli, S., Bozoğlu, Ş. \& Cedden, F., 2015. Effect of different harvesting techniques on recovery and quality of cattle cumulus oocyte complex. Iranian J. Appl. Anim. Sci. 5, 185-188.

Chatot, C., Ziomek, C., Bavister, B., Lewis, J. \& Torres, I., 1989. An improved culture medium supports development of random-bred 1-cell mouse embryos in vitro. J. Reprod. Fertil. 86, 679-688.

Chaves, R.N., Martins, F.S., Saraiva, M.V.A., Celestino, J.J.H., Lopes, C.A.P., Correia, J.C., Lima-Verde, I.B., Matos, M.H.T., Báo, S.N., Name, K.P.O., Campello, C.C., Silva, J.R.V. \& Figueiredo, J.R., 2008. Chilling ovarian fragments during transportation improves viability and growth of goat preantral follicles cultured in vitro. Reprod. Fertil. Dev. 20, 640-647.

Choi, Y., Love, L., Varner, D. \& Hinrichs, K., 2006. Holding immature equine oocytes in the absence of meiotic inhibitors: effect on germinal vesicle chromatin and blastocyst development after intracytoplasmic sperm injection. Theriogenology 66, 955-963.

Das, G., Jain, G., Solanki, V. \& Tripathi, V., 1996. Efficacy of various collection methods for oocyte retrival in buffalo. Theriogenology 46, 1403-1411.

De Mendiburu, F., 2014. Agricolae: Statistical Procedures for Agricultural Research. Lima, Peru: National Engineering University. 
Evecen, M., Cirit, Ü., Demir, K., Özdaş, Ö.B., Taş, M., Birler, S. \& Pabuccuoğlu, S., 2010. Effects of estrous cycle stage and transport temperature of ovaries on in vitro maturation of canine oocytes. Anim. Reprod. 117, 160-165.

Guignot, F., Bezard, J. \& Palmer, E., 1999. Effect of time during transport of excised mare ovaries on oocyte recovery rate and quality after in vitro maturation. Theriogenology 52, 757-766.

Jewgenow, K., Penfold, L., Meyer, H. \& Wildt, D., 1998. Viability of small preantral follicles from domestic cats after cryoprotectant exposure and cryopreservation. J. Reprod. Fertil. 112, 39-47.

Kim, H.J., Choi, S.H., Son, D.S., Cho, S.R., Choe, C.Y., Kim, Y.K., Han, M.H., Ryu, I., Kim, I.C., Kim, I., Im, K.S. \& Nagai, T., 2006. Effect of exposure duration of ovaries and oocytes at ambient temperature on partheno-genetic development of porcine follicular oocytes. J. Reprod. Dev. 52, 633-638.

Kobayashi, K., Yamashita, S. \& Hoshi, H., 1994. Influence of epidermal growth factor and transforming growth factor- $\alpha$ on in vitro maturation of cumulus cellenclosed bovine oocytes in a defined medium. J. Reprod. Fertil. 100, 439-446.

Lin, Y.-A., Tsai, H.-B., Liao, M.-H. \& Chen, M.-C., 2011. Effects of preservation media on in vitro maturation of porcine oocytes. Chin. J. Physiol. 54, 1-6.

Lopes, C.A.P., Santos, R.R., Celestino, J.J.H., Melo, M.A.P., Chaves, R.N., Campello, C.C., Silva, J.R.V., Báo, S.N., Jewgenow, K. \& Figueiredo, J.R., 2009. Short-term preservation of canine preantral follicles: Effects of temperature, medium and time. Anim. Reprod. Sci. 115, 201-214.

Love, L.B., Choi, Y.H., Love, C.C., Varner, D.D. \& Hinrichs, K., 2003. Effect of ovary storage and oocyte trasport method on maturation rate of horse oocytes. Theriogenology 59, 765-774.

Manjunatha, B., Gupta, P., Ravindra, J., Devaraj, M. \& Nandi, S., 2008. In vitro embryo development and blastocyst hatching rates following vitrification of river buffalo embryos produced from oocytes recovered from slaughterhouse ovaries or live animals by ovum pick-up. Anim. Reprod. Sci. 104, 419-426.

Martino, A., Songsasen, N. \& Leibo, S., 1996. Development into blastocysts of bovine oocytes cryopreserved by ultra-rapid cooling. Biol. Reprod. 54, 1059-1069.

Matsushita, S., Tani, T., Kato, Y. \& Tsunoda, Y., 2004. Effect of low-temperature bovine ovary storage on the maturation rate and developmental potential of follicular oocytes after in vitro fertilization, parthenogenetic activation, or somatic cell nucleus transfer. Anim. Reprod. Sci. 84, 293-301.

Mattioli, M., Galeati, G., Bacci, M. \& Seren, E., 1988. Follicular factors influence oocyte fertilizability by modulation intercellular cooperation between cumulus cells and oocyte. Gamete Res. 21, 223-232.

Neglia, G., Gasparrini, B., Caracciolo di Brienza, V., Di Palo, R., Cam-panile, G., Presicce, G.A. \& Zicarelli, L., 2003. Bovine and buffalo in vitro embryo production using oocytes derived from abattoir ovaries or collected by transvaginal follicle aspiration. Theriogenology 59, 1123-1130.

Niemann, H., 1991. Cryopreservation of ova and embryos from livestock: current status and research needs. Theriogenology 109-124.

Nureddin, A., Epsaros, E. \& Kiessling, A., 1990. Purines inhibit the development of mouse embryos in vitro. J. Reprod. Fertil. 90, 455-464.

Patel, K.K., Hartmann, F. \& Cohen, M.M., 1973. Effect of pH on metabolism and ultrastructure of guinea pig cerebral cortex slices. Stork 4, 221-231.

Pedersen, H., Watson, E. \& Telfer, E., 2004. Effect of ovary holding temperature and time on equine granulosa cell apoptosis, oocyte chromatin configuration and cumulus morphology. Theriogenology 62, 468-480.

Rahman, A.N.Md.A., Abdullah, R.B. \& Embong, W.K.W., 2007. Goat embriyo development from in vitro matured oocytes of hetrogeneous quality through intracytoplasmic sperm injection technique. Biotechnology 6, 373-382.

Rodriguez-Dorta, N., Cognié, Y., González, F., Poulin, N., Guignot, F., Touzé, J., Baril, G., Cabrera, F., Álamo, D., Batista, M., Gracia, A. \& Mermillod, P., 2007. Effect of co-culture with oviduct epithelial cells on viability after transfer of vitrified in vitro produced goat embriyos. Theriogenology 68, 908-913.

Salehi, P., Spratlin, J., Chong, T.-F. \& Churchill, T.A., 2004. Beneficial effects of supplemental buffer and substrate on energy metabolism during small bowel storage. Cryobiology 48, 245-253.

Schernthaner, W., Schmoll, F., Brem, G. \& Schellander, K., 1997. Storing bovine ovaries for 24 hours between 15 and $21^{\circ} \mathrm{C}$ does not influence in vitro production of blastocists. Theriogenology 47 , 297-297.

Schini, S. \& Bavister, B., 1988. Two-cell block to development of cultured hamster embryos is caused by phosphate and glucose. Biol. Reprod. 39, 1183- 1192.

Schomack, P.A. \& Gillies, R.J., 2003. Contributions of cell metabolism and $\mathrm{H}+$ diffusion to the acidic $\mathrm{pH}$ of tumors. Neoplasia 5 (2), 135-145. 
Seefeld, K. \& Linder, E., 2007. Statistics using R with biological examples. Durham: University of New Hampshire, UK.

Shi, L., Yue, W., Zhang, J., Lv, L., Ren, Y. \& Yana, P., 2009. Effect of ovarian cortex cells on nuclear maturation of sheep oocytes during in vitro maturation. Anim. Reprod. Sci. 113, 299-304.

Silva, J.R.V., Lucci, C.M., Carvalho, F.C.A., Biio, S.N., Costa, S.H.F., Santos, R.R. \& Figueiredo, J.R., 2000. Effect of coconut water and braun-collins solutions at different temperatures and incubation times on the morphology of goat preantral follicles preserved in vitro. Thenogenology 54, 809-822.

Silva, J.R.V., Hurkb, R.V.D., Costa, S.H.F., Andrade, E.R., Nunes, A.P.A., Ferreira, F.V.A., Lôbo, R.N.B. \& Figueiredo, J.R., 2004. Survival and growth of goat primordial follicles after in vitro culture of ovarian cortical slices in media containing coconut water. Anim. Reprod. Sci. 81, 273-286.

Smith, C., Peter, A. \& Pugh, D., 1994. Reproduction in llamas and alpacas: A review. Theriogenology 41, 573-592.

Soto, P., Natzke, R. \& Hansen, P., 2003. Identification of possible mediators of embryonic mortality caused by mastitis: Actions of lipopolysaccharide, prostaglandin F2a, and the nitric oxide generator, sodium nitroprusside dihydrate, on oocyte maturation and embryonic development in cattle. AJRI. 50, 263-272.

Taş, M., Evecen, M., Özdas, Ö.B., Cirit, Ü., Demir, K., Birler, S. \& Pabuccuoğlu, S., 2006. Effect of transport and storage temperature of ovaries on in vitro maturation of bitch oocytes. Anim. Reprod. Sci. 96, 30-34.

Thibodeaux, J.K., Myers, W., Goodeaux, L.L., Ménézo, Y., Roussel, J.D., Broussard, R. \& Godke, R.A., 1992. Evaluating an in vitro culture system of bovine uterine and oviduct epithelial cells for subsequent embryo co-culture. Reprod. Fertil. Dev. 4, 573-583.

Thompson, J., Simpson, A., Pugh, P. \& HR., T., 1992. Requirement for glucose during in vitro culture of sheep preimplantation embryos. Mol. Reprod. Dev. 31, 253-257.

Thouas, G., Korfiatis, N., French, A., Jones, G. \& Trounson, A., 2001. Simplified technique for differential staining of inner cell mass and trophectoderm cells of mouse and bovine blastocysts. Reprod. Biomed. Online 3 (1), 25-29.

Ubaidullah, L.A.L., Ahmad, S., Sultan, S. \& Khan, Y., 2009. In vitro maturation of oocytes in different maturation media containing oestrous buffalo serum, oestrous cow serum and follicular fluid from buffalo. Pak. J. Zool. 9 (Suppl. Ser.), 213-218.

Wang, Y.S., Zhao, X., Su, J.M., An, Z.X., Xiong, X.R., Wang, L.J., Liu, J., Quan, F.S., Hua, S. \& Zhang, Y., 2011. Lowering storage temperature during ovary transport is beneficial to the developmental competence of bovine oocytes used for somatic cell nuclear transfer. Anim. Reprod. Sci. 124, 48-54.

Wani, N., Wani, G., Khan, M. \& Salahudin, S., 2000. Effect of oocyte harvesting techniques on in vitro maturation and in vitro fertilization in sheep. Small Rumin. Res. 36, 63-67.

Westhof, G., Westhof, K., Braendle, W. \& Dizereca, G., 1991. Differential steroid secretion and gonadotropin response by individual tertiary porcine follicle in vitro: Possible physiologic role of atretic follicles. Biol. Reprod. 44, 461-468.

Whitaker, B. \& Knight, J., 2004. Exogenous g-glutamyl cycle compounds supplemented to in vitro maturation medium influence in vitro fertilization, culture, and viability parameters of porcine oocytes and embryos. Theriogenology 62, 311-322.

Wongsrikeao, P., Otoi, T., Karja, N., Agung, B., Nii, M. \& Nagai, T., 2005. Effects of ovary storage time and temperature on DNA fragmentation and development of porcine oocytes. J. Reprod. Dev. 51, 87-97.

Yang, M.R., 2002. Expression of Bcl-2 and Bax proteins in relation to quality of bovine oocytes and embryos produced in vitro. Anim. Reprod. Sci. 70, 159-169.

Yuge, M., Otoi, T., Nii, M., Murakami, M.K., Karja, N.W.K., Rajaei, F., Agung, B., Wongsrikeao, P., Murakami, M. \& Suzuki, T., 2003. Effects of cooling ovaries before oocyte aspiration on meiotic competence of porcine oocytes and of exposing in vitro matured oocytes to ambient temperature on in vitro fertilization and development of the oocytes. Cryobiology 47, 102-108. 